\title{
LASER SCANNING AND MODELLING OF BARELY VISIBLE FEATURES: THE SURVEY OF THE GROTTO OF THE ANIMALS AT THE VILLA OF CASTELLO (FLORENCE)
}

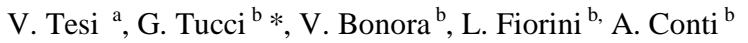 \\ ${ }^{\text {a }}$ Soprintendenza Archeologia Belle Arti e Paesaggio per la città metropolitana di Firenze e per le province di Pistoia e Prato, Piazza \\ Pitti, 1 - 50125 Firenze, Italy - valerio.tesi@beniculturali.it

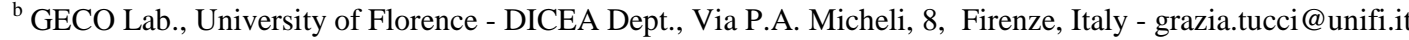

KEY WORDS: Mannerist gardens, Artificial grottoes, Ancient hydraulic systems, Laser scanner, Mesh modelling.

\begin{abstract}
:
The deep fusion of natural and artificial elements typical of Italian Renaissance gardens is particularly evident in the park of Villa di Castello and in the Grotto of the Animals, also called Grotto of the Flood.

The soil slope is the essential element of a huge underlying hydraulic machine and it is the result of extensive earthworks which led to the construction of the big retaining wall limiting the grotto and the adjacent fountains. Hence, this grotto represents only the visible part of a mechanism running all around it. It is formed by a single chamber vaulted and covered with sponge-like stones, as well as decorations made of pebbles and shells. The space is divided into three wings, with big marble basins at their end. Over them there are reliefs of animals made of different stones and marbles. Animals recur also in the compositions of fish and shellfish decorating the side basins and in the bronze birds currently kept in the Museo del Bargello.

The name "Grotto of the Flood" comes from the water feature that characterised this place: visitors were surprised by tens of jets hidden among the stones in the vault and in the floor. To obtain this effect, the whole grotto is surrounded by multi-storey tunnels, hiding the hydraulic system and people activating the mechanisms. Research agreements were drawn up between the Special Superintendence for the Historical, Artistic and Ethnoanthropological Heritage, the Florence museums group and the GeCO Lab, for the realization of the survey presented in this paper. The task of the GeCO Lab was thus identifying the best solutions to check the spatial relations between the grotto and the area above, as well as the geometric and functional connections between the building and the ancient hydraulic system, composed by pipes and nozzles concealed between the stones. Besides, the overall survey was intended as a documentation of the on-going restoration work.
\end{abstract}

\section{INTRODUCTION}

The in-depth study of Cultural Heritage undoubtedly requests demanding investments, so is usually carried out at "special events". Although the current approach favours regular maintenance that avoids more radical one-off interventions, it is common that a documentation project is undertaken during a restoration work.

In recent years, "geomatics for conservation" has been developed to rapidly produce comprehensive and reliable threedimensional representations of Cultural Heritage. Starting from the interpretation of geometries based on their spatial positioning, in a suitable reference system, it has developed specific skills, always highlighting the primary importance of the "measure" and of its "quality" both for the description of the factual situation and for the examination of the risk factors to which the built heritage is exposed, both for the purpose of safeguarding and for developing maintenance and prevention programs of the expected damage. The survey carried out by the GeCO Lab for the Superintendence for the Historical, Artistic and Ethnoanthropological Heritage provided an interesting and positive cause for reflection to establish a dialogue between "users" and "providers" of metric data and create a common ground to set up appropriate intervention programs.

\section{THE SURVEY OF MANNERIST GROTTOES AND GARDENS}

Among the arts of the 16th century, gardens are one of the most peculiar forms, thanks to the fountains, grottoes and nymphaea "coperti di colature d'acqua pietrificate, che pendono a guisa di radicioni" ("covered with stalactites from petrified waterflows, which hang down resembling roots," according to Vasari's trenchant description, Vasari 1568) that instantly characterise them.

In the past, the need to exhaustively document such important works often collided with the difficulty to survey and render (except by means of simplifications or stylizations) their organic shapes. The new survey techniques, through high resolution sampling, can help overcome these critical aspects and obtain realistic and metrically valid representations, regardless of the complexity of the represented geometry. The GeCO Laboratory has faced this challenge many times, detecting specific operating workflows to survey and render organic and natural shapes, which have been tested while surveying most art-works in the Medici Park of Pratolino, including the Appennino statue by Jean de Boulogne, which is the most representative work (Tucci 1999, Tucci et al. 2012, Tucci et al. 2013). 


\section{THE GROTTO OF THE ANIMALS AT THE VILLA OF CASTELLO (FLORENCE): HISTORICAL NOTES}

In his Lives, Giorgio Vasari narrates at length on the work that the artist Niccolò Pericoli, aka Tribolo, undertook at Castello for Cosimo I, providing a most attentive description of the intricate iconographic design that the young Medici duke wanted to create in the garden there. With such a complex layout, and so many decorative devices, the estate became a place for experimentation and the initial model for the Medici gardens to come, despite being incomplete and only seen through in part, as Vasari himself notes: "All these ornaments would have made this in truth the richest, the most magnificent, and the most ornate garden in Europe; but these works were not carried to completion.” (Vasari 1568).

What is certain is that, as of 1538 , namely straight after his election as Duke of Florence on 9 January 1537, Cosimo I would promote a majestic series of works at Villa di Castello, place of his childhood together with the Mugello villas. Of these, the immense groundworks were the greatest undertaking, alongside the definition of the garden, its hydraulic system, and its architectural and botanic features. The garden's elaborate fixtures and sculptures were to form an incredible set of symbols meant to represent the Florentine state and "the complete absorption of the Duke's territory under Florence, and of both under the house of the Medici, in the eternal cycle of Time" (Acidini and Galletti 1992, p.42).

The garden is laid out on descending levels, with a large drop from the level of the Appennino statue and the 'wild area', with the trapezoidal nursery beds, to the lower level of the grotto, which bears witness to the immense excavation and terracing work performed on the original land mass, truly impressive for sixteenth-century technology.

It is in this drop that the Grotto of the Animals is found, which, while the place of greatest figurative expression in the presentday garden, does not reflect what must have been its original appearance. Its architectural structure, on the other hand, with the side corridors and their vaults, substantially acts as a system to contain the soil.

The structural layout of the grotto and its water pipes are to be attributed to Tribolo, even though it was completed under the guidance of Giorgio Vasari; the decorative sculptures were also finished a long time after Niccolò Pericoli's death, with the collaboration of Jean de Boulogne and Ammannati, probably following a very different design to what was initially planned. Owing to the different figures involved, today this extraordinary place can be interpreted in many different ways, despite the readings of critical studies from recent decades and the numerous proposed interpretations of the iconological design which seem to revolve around its 'evocation of the three kingdoms of living beings' portrayed through 'sculptures of animals of the water, earth and air'. These are situated both in the three large niches that the grotto branches out into, and in the vaults clad in sponge-like 'tufa' limestone, originally home to bronze sculptures of birds and fowl (Acidini and Galletti 1992, p.45).

The stone encrustations on the walls hide a series of small cavities here and there. Almost like a vase in shape, they are thought to have been used to house plants, fed by the steady trickle of water down the walls. They were a further expression of the intimate connection and lifeblood linking the mineral kingdom of the 'icy waters' and stone ornaments to the animal kingdom at whichever latitude (Fig. 1).

At the end of the sixteenth century, Gustav Utens vividly described the details of the garden at Villa di Castello in his famous lunette, showing the entrance to the grotto and the two side niches in the headwall, all clad in tufa. This appearance would remain substantially the same into the eighteenth century when the Lorraine family had far-reaching changes made to the design and structure of the garden, as was also echoed in the Grotto of the Animals.

The report written in 1745 on the 'Work to be done on the Buildings and Fountains of His Imperial Majesty’ describes the conditions of near-abandonment of the garden. The report indicates how 'at the Grotto in the Garden there is a ceiling that is totally ruined, with all the niches missing' (Acidini and Galletti 1992). In other words, the inevitable infiltrations of rainwater from above had made the mortar fixing together the different materials break down, causing most of the shell decorations to fall off.

It is in this phase that, in addition to the recuperation and extensive reconstruction of the internal decorations, a radical operation was carried out on the grotto roof. This consisted of using concrete to seal the vaults and upper pipes, that is, two earthenware conduction channels on either side of the grotto, with lead tubes branching off through sandstone fittings. The original hydraulic system crisscrossed the whole roof with a network of over one hundred narrow lead pipes or 'canne'. These ran through the brickwork vaults up to the nozzles, again made of lead, hidden by the tufa cladding. Originally, these dripped water down inside the grotto, like rainfall, in contrast to the jets of water sprayed from the fine nozzles set in the floor.

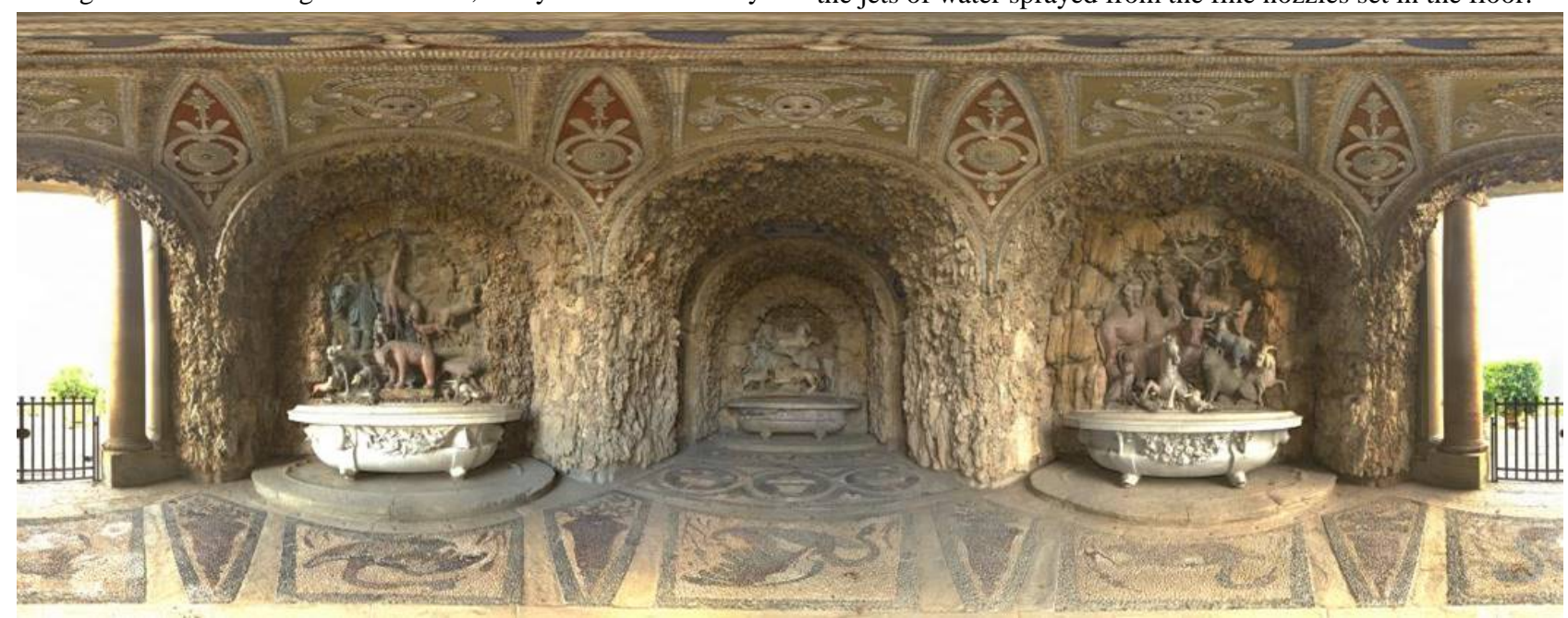

Figure 1. The Grotto of Animals. Panoramic image. 
When the floor of the terrace above the grotto was covered with paving stones in 1779, under the direction of Bernardo Fallani, the earthenware conduction network, the sandstone fittings and the lead piping, which probably no longer worked at the time, were concealed once and for all. And so a fundamental component of the sixteenth-century hydraulic system was lost, along with the grotto's picturesque water features, as evoked in Vasari's description of the Villa di Castello garden in the introduction to On Technique: 'and thus are arranged pipes for water and various jets through which the water rains down among the incrustations of these stalactites, and in falling sounds sweet to the ear and is beautiful to the eye' (Vasari 1568).

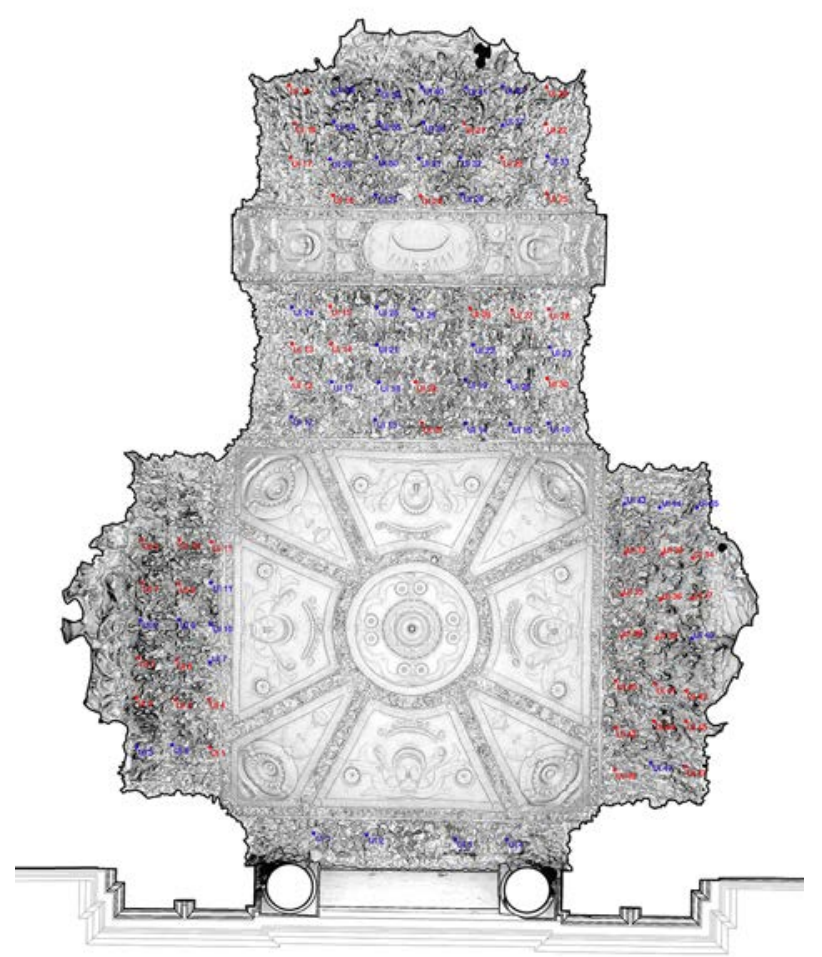

Figure 2. The vault with the position of the nozzles.

\section{THE RESTORATION PROJECT}

At various points in the mid 1990s the Superintendence for the Cultural Heritage carried out restoration activities on the grotto. These brought to light a large part of the hydraulic system found in the extrados of the roof of the innermost vault. However, the Superintendence was unable to complete the work or outline possible solutions for cleaning up the area and potentially reactivating the hydraulic system ${ }^{1}$.

More recently, a new phase of restoration work was prompted by new deterioration of the different internal decoration materials, and the tufa and decorations falling down. This work

1 Since the early 1990s the Superintendence for the Architectural and Environmental Heritage has implemented a series of restoration works, begun by Cristina Acidini and then continued by Isabella Lapi Ballerini and Giorgio Galletti; the latter must be thanked for the retrieval of a large part of the piping in the extrados of the innermost vault. 'During the 1994 restoration work on the Grotto of the Animals trials were made on the extrados of the vault which enabled the removal of a reinforced concrete roof made in the 1970s, and a chiselled stone pavement...Underneath this flooring was a thick layer of lime mortar conglomerate incorporating the sixteenth-century hydraulic system’, (Galletti 2001, p.159, no.37). is currently underway, in spite of the discontinuity and difficulties caused by the permanent state of reorganization of the peripheral cultural heritage departments and their fields of competence $^{2}$

After a first, initial phase in which the various internal decorations were made safe and restored, a series of investigations and progressive inspections were begun ${ }^{3}$ to carefully bring to light the whole hydraulic system and its layout above the vaults of the grotto. The aim was then to understand how it originally worked in order to assess whether the water features could be reactivated as well as possible solutions for the grotto roof in relation to the current layout of the Appennino level.

In particular, the first task was to identify if what still remains in the grotto vaults of the studied layout of the water nozzles corresponds with the network of tubes found in the extrados. While seemingly banal, it is not given that they correspond, also owing to the distortions experienced over time both by the hydraulic system and the internal decorations (Fig. 2).

Hence, it was ascertained that there are also some lead pipes above the cross vault of the entrance to the grotto set out along the centre-line of each haunch. Nevertheless, these do not correspond to any nozzles in the internal vault, bearing witness to the changes and alterations to the decorations themselves, probably made during the Lorraine era, which indeed do not

2 After some blocks of tufa fell inside the grotto, in 2012 the Special Superintendence for the Historical, Artistic and Ethnoanthropological Heritage and the Florence museums group implemented urgent intervention work, of which I was in charge. I would like to thank the superintendent Cristina Acidini and architect Mauro Linari for their invitation to collaborate and direct the works. After this first urgent intervention, a second phase of restoration was begun, guided by myself and the team of colleagues Alessandra Griffo, Hosea Scelza and Rosella Pascucci, with Chiara Tettamanti in the role of head of proceedings, followed by Corrado Azzolini, Paola Ruggieri and now Hosea Scelza. May I thank them all and show my sincere appreciation for their collaboration and participation in sharing the planning and operating choices. The reason for such a long list of names and roles is also because the work was first of all directed by the Special Superintendence mentioned above, and then the Tuscany museums group, headed by director Stefano Casciu, whom I thank together with the current museum director of the Villa di Castello royal garden, Marco Mozzo. I would like to thank them, as well as superintendent Alessandra Marino, who has followed the last phase of the restoration work, for the attention paid to the work underway. (note by V.T.).

3 Research agreements were drawn up between the Special Superintendence for the Historical, Artistic and Ethnoanthropological Heritage, the Florence museums group and the GeCO Lab, for the realization of the survey presented in this paper. Further agreements were made with the Institute for the Conservation and Promotion of Cultural Heritage (ICVBC) in order to identify the building materials used and their chemical and physical characteristics (mortar, natural and artificial stone, glass, plaster, dye pigments and organic elements) and to isolate the materials used in the restoration work carried out between the eighteenth and twentieth centuries, so that the sequence of layers of materials both inside the grotto and above the vaults could be interpreted as far as possible; to this end, microbores with the smallest possible section were made at three points in the extrados of the vaults (stopping at the top of the brickwork of the vaults), in order to identify any changes in the materials making up the layers of concrete. Furthermore, analysis of the state of preservation of the materials will be correlated to studies of the environmental conditions inside the grotto, with monitoring of the temperature and humidity, also with a view to potentially reactivating the water features. 
present any relationship with the position of the lead pipes now discovered in the extrados.

This fact is another reason for acquiring a detailed survey of the grotto, as described further on in this paper in addition to the vaults, the survey will also be extended to the mighty structure of the side passageways and perhaps also be used to retrace the water collection and discharge system. Consisting of a network of small gutters underneath the gravel floor leading into a central duct, it crosses the whole grotto to then widen and continue below ground towards the fountain of Hercules and Antaeus.

The survey enabled the actual thickness of the grotto walls to be checked in the whole vaulted area. This meant that the operations to cut and remove the concrete to find the remains of the hydraulic system could be outlined and checked with particular care. What was discovered in the part corresponding to the first vault proved to be a lot more fragmentary than what had been found in 1995 (Fig. 3).

The survey operations and the acquisition methods resulted in a 3D representation of the whole hydraulic system, from the conduction pipes to the outflow system, giving an immediate and effective visual description of how the ingenious hydraulic machinery worked.

As Giorgio Vasari wrote, the water falling inside the grotto 'sounds sweet to the ear and is beautiful to the eye'. Therefore, so as to restore a fundamental part of the elements making up the Grotto of the Animals, the next task was how the hydraulic system in the extrados could be reactivated.

First of all, after a series of cautious tests, the narrow lead pipes threading through the vaults, blocked by encrustations, deposits and materials that had hardened in time, were reopened by making perforations from the inside.

The original lead tubes, the system of earthenware ducts, comprising truncated cone elements slotted into each other, and the stone junctures into which the ducts and pipes were inserted were in a serious state of decay. As a result, it was not possible to preserve them. All the lead tubes were dismantled and removed, also in order to check the exact position of the rainfall nozzles and go on to reopen the pipes.

Instead of replicating the sixteenth-century loop system, it was preferred to adopt a different method to conduct the water to the rainfall nozzles. Every nozzle inside the grotto was given new autonomous and independent tubing connected to new collectors in the side ducts of the grotto to conduct the water. As a result, precise checks can be made of the water pressure and the system is easy to maintain ${ }^{4}$.

Finally, having a 3D model of the grotto also makes it possible to recreate, at least virtually, the original image of the grotto as it was and all its decorations. As early as 1992, in her account of the removal of the bronze menagerie depicting the kingdom of the air, which had led to 'a particularly unseemly and displeasing emptiness', Cristina Acidini very deliberately proposed 'to consolidate and restore the environment [with] faithful copies [...] of all the birds, to be installed in the ceiling so as to rebuild all of the original iconography and symbols' (Acidini and Galletti 1992, p. 120).

Despite its complexity, thanks to the 3D model of the Grotto of the Animals, it is now easy to fulfil this fascinating suggestion

4 Only a tiny part of the original water nozzles have been preserved in the vaults of the grotto: one of the reasons for their disappearance in the past was to retrieve the lead for wartime needs. The shape of the original elements, as well as the number of nozzles present, has been replicated based on a series of tests. Their size, so to enable the water to fall like rain, is also known thanks to the tests. in the virtual reality dimension, and indeed the idea could easily be extended to the bronze figures presently housed in museums.

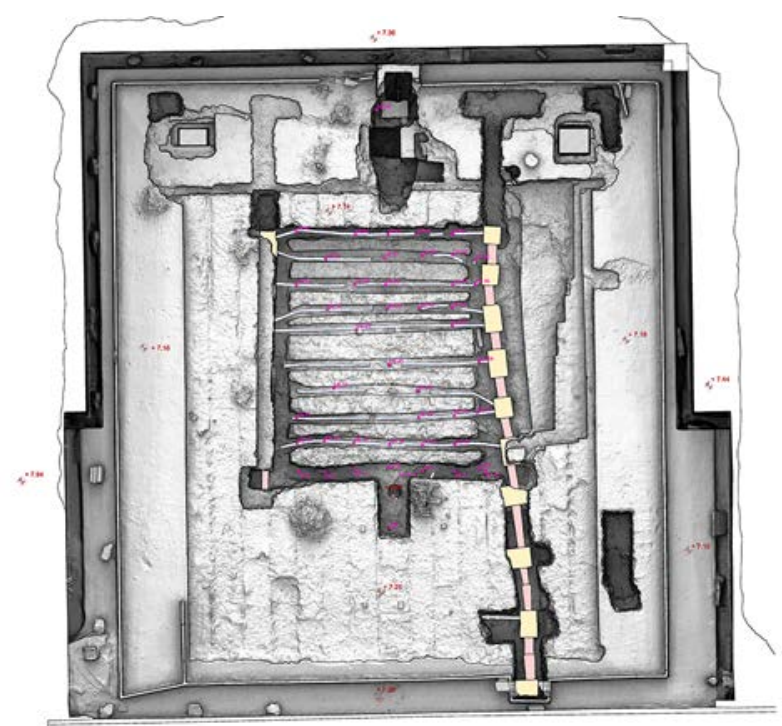

Figure 3. Plan of the terrace above the Grotto with the ancient hydraulic system.

\section{THE SURVEY OF THE GROTTO}

The identification of small elements, barely visible inside a particularly uneven geometry, shows how the survey cannot be considered as a merely passive collection of "big data" to be assessed subsequently, even if it is carried out with tools that automatically acquire a huge quantity of data. When an acquisition of spatial data represents the foundation of wider projects and valorisation activities, it always entails deep comprehension of every aspect of the works of art. Besides, this extensive study is the starting point of the real survey project, whose aim is identifying the most suitable operating modes according to the specificity of the measurand and the metrology features of the tools.

\begin{tabular}{|l|l|}
\hline Project & Grotto of the Animals \\
\hline Location & Villa Reale di Castello - Florence \\
\hline Dimensions & $13 \mathrm{~m}$ x $8 \mathrm{~m}$ x $8 \mathrm{~m}$ \\
\hline Instruments & $\begin{array}{l}\text { Total station: Leica TCR303 } \\
\text { Laser scanners: Leica HDS6000 and C10 } \\
\text { SLAM scanner: GeoSLAM Zeb-1 } \\
\text { Cameras: Nikon D90, Nikon D700 } \\
\text { Panoramic head: Gigapan EPIC Pro }\end{array}$ \\
\hline Software & $\begin{array}{l}\text { Topography: Star*Net } \\
\text { Scans processing: Cyclone Leica } \\
\text { Mesh processing: ISTI-CNR MeshLab } \\
\text { CAD: Bentley Microstation } \\
\text { Panoramas processing: Gigapan Stitch }\end{array}$ \\
\hline
\end{tabular}

Table 1. Summary of project data and tools

\subsection{First stage: the vault and the topographic network}

The survey was divided into different stages. During the first stage, we surveyed the entire retaining wall and the vaults of the grotto from a close distance, using the scaffolding installed to 
carry out maintenance work, which enabled a careful inspection to visually detect the position of the nozzles (Fig. 2).

Even though the area is small (it is formed by a single chamber, approx. $13 \mathrm{~m} \times 8 \mathrm{~m}$ and $8 \mathrm{~m}$ high), we created a topographic control network first, as we thought that the study would have been carried out only subsequently, according to the instructions given by the preparatory work. With the help of the total station we identified the positions of the 4 vertices, firmly marked on the ground. As is well known, the measurement process moves "from general to detail": so, starting from the vertices of the control network we measured the control points to reference the detail data acquired during the different subsequent stages.

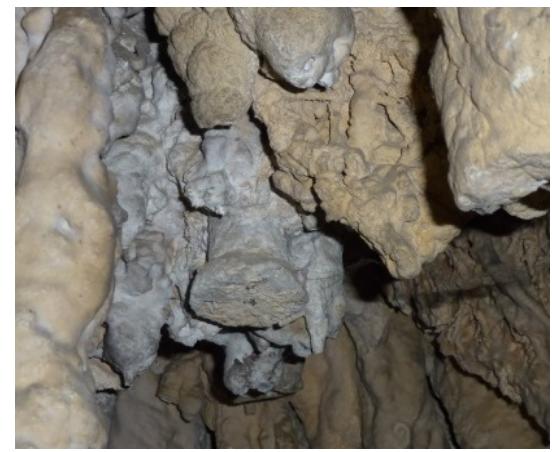

Figure 4. A lead nozzle among the stones of the vault.

\subsection{Surveying hardly visible features}

The nozzles are made of small diameter lead pipes (some of them still equipped with the perforated diffuser) deeply embedded among the porous stones of the vault, so that they are barely visible (Fig. 4). To easily identify them, we placed small paper cuts fixed by means of a wire (Fig. 5).

To detect their position, we chose to perform several close-up scans at pseudo-nadir position within the interested areas, in order to carefully acquire every recess and avoid the formation of shadow points with no data. The number of scans (26) is thus higher than the general one for spaces having the same size.

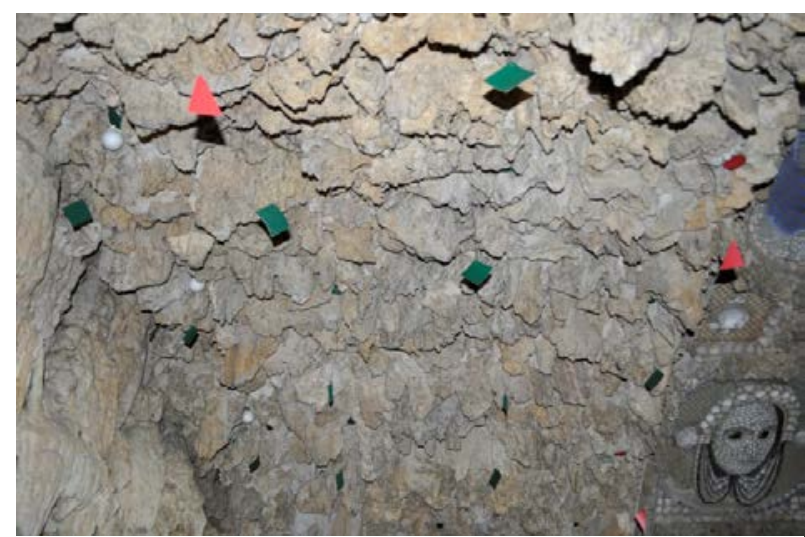

Figure 5. Paper flags used to highlight the nozzles in the vault.

\subsection{Second stage: the grotto}

During the second stage we surveyed the whole grotto after having removed the scaffolding. On the floor, we placed foam spheres next to the jets hidden among the pebbles to simplify their identification in the scans (Fig. 6).

\subsection{Third stage: the ancient hydraulic system}

The third stage was carried out to survey the terrace above the Grotto after removing the temporary cover and after having performed new excavations that brought to light a larger portion of the ancient system network, embedded in lime concrete. It was made of terracotta pipes connected by means of monolithic elements made of stone to smaller lead pipes, which were laid out in a comb shape and ended with a nozzle (Fig. 3). In this case too, before laser scanner acquisitions we visually inspected the space, placing foam balls next to the branches and the significant points that could have been less evident in the scans.

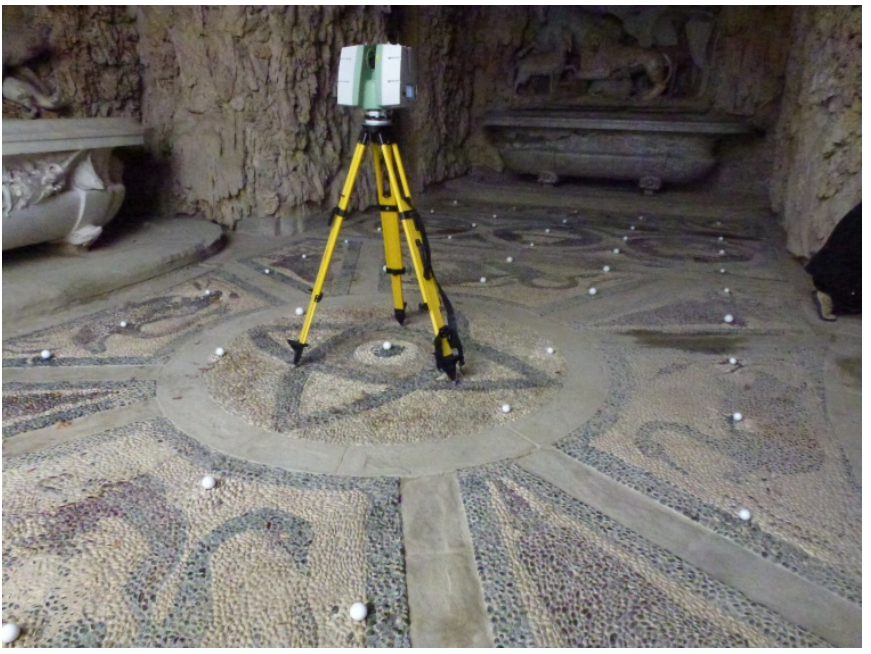

Figure 6. Foam balls on the nozzles in the floor.

\subsection{Fourth stage: testing a SLAM system in the tunnels}

The last stage was the acquisition of portions of the tunnels in the retaining wall thickness. These spaces, whose geometry represents a real hydraulic machine in itself, are difficult to access, as these are very narrow passages communicating to the outside through hidden small doors. For this reason, instead of using the terrestrial laser scanner of the previous stages, we tested the hand-held mobile scanning system Zeb-1 by GeoSLAM.

\begin{tabular}{|c|c|c|c|c|}
\hline 䒕 & $\stackrel{\Xi}{2}$ & 气ี & 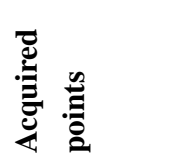 & 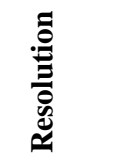 \\
\hline $\begin{array}{l}9- \\
10 / 08 / 12\end{array}$ & $\begin{array}{l}\text { Top. network, } \\
\text { vault, ret. wall }\end{array}$ & 26 & $370,714,688$ & $\begin{array}{l}5 \mathrm{~mm} \text { at } \\
5 \mathrm{~m}\end{array}$ \\
\hline 05/02/13 & Grotto & 8 & $369,353,135$ & $\begin{array}{l}5 \mathrm{~mm} \text { at } \\
5 \mathrm{~m}\end{array}$ \\
\hline $\begin{array}{l}09 / 10 / 13- \\
10 / 09 / 15\end{array}$ & $\begin{array}{l}\text { Hydraulic } \\
\text { system }\end{array}$ & $\begin{array}{l}18 \\
25\end{array}$ & $\begin{array}{l}713,732,636 \\
864,683,723\end{array}$ & $\begin{array}{l}6.3 \mathrm{~mm} \\
\text { at } 10 \mathrm{~m}\end{array}$ \\
\hline 07/09/15 & Tunnels & & 892,289 & \\
\hline
\end{tabular}

Table 2. Summary of data acquired at different stages

\section{DATA ELABORATION AND DELIVERABLES}

As is known, the computerised techniques of spatial data acquisition which fall under the term "Geomatics" all perform high resolution sampling of the surveyed geometries, producing 


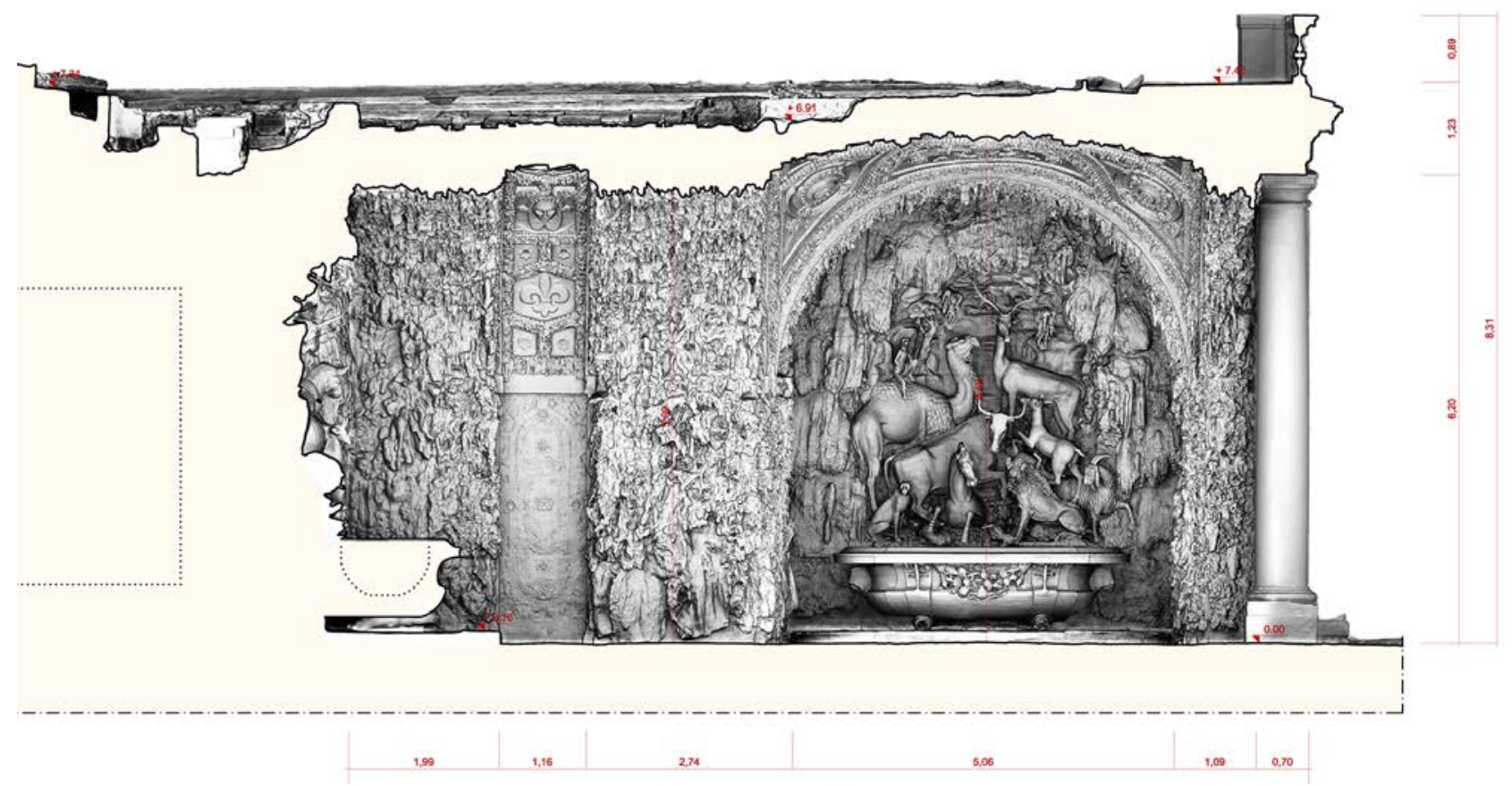

Figure 7. Longitudinal section of the Grotto of Animals.

a database of 3D coordinates so dense it can be used as a visual reference of the object itself (Tucci and Bonora 2015). After having solved the issue linked to the acquisition and the metric reliability of the measures, the only remaining problem concerns the most effective forms of representation according to the collected data.

\subsection{D models and 2D drawings}

In this case the nature of the object itself suggested the solution to adopt: in the Grotto, a rigid architectural and hydraulic structure is hidden among soft naturalistic shapes. Hence, if the organic element can be faithfully represented through 3D modelling, 2D technical representations proved to be the most effective modes to reveal the underlying construction logic. We therefore produced a high resolution mesh model to obtain all the orthogonal views (Fig. 7). Besides, the sections showed that the thickness of the vault is lower than believed.

\begin{tabular}{|l|c|c|}
\hline \multicolumn{1}{|c|}{ Area } & Vertices & Faces \\
\hline Grotto & $29,708,969$ & $59,415,314$ \\
\hline Terrace above grotto & $17,448,313$ & $34,895,942$ \\
\hline
\end{tabular}

Table 3. Summary of meshes data

\subsection{Detection and modelling of the hydraulic system}

As far as the study concerning the study of the water features is concerned, the 3D model allows us to effectively identify the relation between the pipes and the nozzles. We noticed that the pipes have branches also in those areas where nozzles are no longer present, such as next to one of the big masks on the vault and in the strip dividing the longer wing. This is related with old restoration or transformation works affecting the vault decoration. In this case, a digital model can allow designing a new 3D system, simulating its functioning and checking any interferences.

\subsection{Mapping of deterioration and restoration work}

In the light of further maintenance work, the model can be used to spatially define the different information within a 3D environment, e.g. to draw a deterioration map or to detect the points needing restoration. These applications have already been performed by the GeCO Laboratory for the model of the Ratto delle Sabine in the Galleria dell'Accademia in Florence (Tucci et al. 2015a) and for the ceramic decorations of the Ospedale del Ceppo in Pistoia (Tucci et al. 2015b).

\subsection{Virtual and/or augmented reality}

3D data are more and more frequently used for disclosure purposes to a wider audience. An essential distinction as far as their use is concerned is the one between off-site and on-site applications. An effective project concerning the communication and valorisation of Cultural Heritage, especially when the latter is not well known, should not employ off-site applications (like full-immersion virtual reality) to replace a real visit but to pique the curiosity of potential visitors or to live again a previous visit. In case of on-site applications, new media should avoid focusing visitors' attention on purely technical aspects, distracting it from the observation of the real object. If ever, it would be better to use the augmented reality to inspire a more careful vision or to analyse different issues in depth according to the visitors' interests and knowledge, e.g. the animals depicted, the artists and the historical characters, the allegorical meanings, and so on...

\subsection{Virtual tour of the unreachable spaces}

Another possible use of 3D data concerns the possibility of making visitors perceive the complexity of the hydraulic machine operating the Grotto, which would not be possible to make physically visible, anyway. Besides the virtual and/or augmented reality techniques, 3D data can be employed also to produce operation animations, videos and physical models that can be disassembled, made with 3D printers. 


\subsection{Virtual restoration}

The Museo del Bargello houses thirteen birds made of bronze coming from the grotto and removed in 1816 and in 1970 (Heikamp 2006). Through reality-based digital models we could place them back in their original context virtually by means of augmented reality techniques or physically through 3D printed copies. In this case, 3D models would enhance the ability of restorers and researchers to formulate alternative hypotheses and perform dimensional checks to carry out activities based not only on the interpretation of historical documents, but also on the physical characteristics of the artworks.

\section{CONCLUSIONS}

The case study has shown how digital models obtained through new technologies for metric data acquisition, processing and modelling rejoin those areas of preservation and valorisation sometimes referred to as different even from a regulatory point of view. The risk may be that of a spectacularization, useless to the scholars and ineffective for a wider audience. The possibility that models instead convey a new and deeper knowledge derives from the methodological rigor in the transition from data to information, representation and knowledge.

Ultimately, the construction and use of digital models must involve a continuous reference between metric and geometric data to archive sources, construction and material aspects, degradation, diagnostic investigations, and so on. Under the point of view of Geomatics, this requires a strict control over the procedures and the metric quality of the data. Even though digital models let scholars simulate infinite solutions before acting on the real thing, and even when a virtual restoration only is discussed, these actions could affect how the real heritage will be understood in future.

For this reason, it lasts the difficult and delicate task of the restorers to find a balance between a correct restoration and the need to "aim to re-establish the potential unity of the work of art, as long as this is possible without producing an artistic or historical forgery and without erasing every trace of the passage of time left on the work of art" according to the words of Cesare Brandi (Brandi 1963).

\section{REFERENCES}

Acidini Luchinat, C, Galletti, G., 1992. Le ville e i giardini di Castello e Petraia a Firenze. Pacini, Pisa.

Brandi, C, 1963. Teoria del Restauro. Edizioni di Storia e Letteratura, Rome. (Trans. by Ponti, G. and Melucco Vaccaro, A., in Price, N., Kirby Talley, M., Melucco Vaccaro, A. 1996. Historical and Philosophical Issues in the Conservation of Cultural Heritage. Getty Conservation Institute, Los Angeles).

Galletti, G., 2001. Tribolo maestro delle acque dei giardini. In: Niccolò detto il Tribolo tra arte, architettura e paesaggio. Pieri,. E., Zangheri, L., (eds.). atti del convegno, Poggio a Caiano

Heikamp, D., 2006. Uccelli di Bronzo. In: Giambologna. Gli dei, gli eroi. Paolozzi Strozzi, B., Zikos, D., (eds.). Giunti, Firenze.

Tucci, G., 1999. Note sul rilievo dei giardini. In: Giusti M. A. (ed.), I tempi della natura. Restauro e restauri dei giardini storici, EDIFIR, Firenze.
Tucci G., Conti A., Fiorini L., 2012. Geomatics for Knowledge and Conservation of Cultural Heritage: The Pratolino Park Case-Study, Proceedings of the 1st International Congress ICONARCH, "Architecture and Technology", Konya, Turkey, pp. $428-440$

Tucci G., Conti A., Fiorini L., 2013. Scansione laser per il rilievo dei giardini storici. Geomedia, 17, 6/2013, MediaGEO, 2013, 1128-8132, pp. 14-18.

Tucci G., Conti A., Fiorini L., 2015a. The Mock-up of the "Ratto Delle Sabine" by Giambologna: Making and Utilization of a 3D Model, ICONARP, 2, 2015, 2147-9380, pp. 73-83

Tucci G., Bonora V., Conti A., Fiorini L., 2015b. Benchmarking range-based and image-based techniques for digitizing a glazed earthenware frieze. Proceedings of the 25rd International CIPA Symposium, Volume II-5/W3, Taipei, Taiwan, 2015, pp. 315-322

Tucci, G., Bonora, V., 2015. Geomatics and management of atrisk cultural heritage. Rendiconti Lincei, 26, pp. 105-114.

Vasari, G., 1568. Le Vite..., Giunti, Firenze. (Trans. by De Vere, G. Lives... Warner, London, 1912-14 and by Maclehose L.C., 1960 On Technique. Dover Publ., New York). 